\title{
PERSONAL PSYCHOLOGICAL PECULIARITIES OF PRE-SCHOOL AGE CHILDREN
}

\author{
'Taydjanova Malika Muratovna \\ ${ }^{2}$ Aliyeva Umida Sobirovna \\ ${ }^{3}$ Agzamova Shoira Abdusalamovna \\ ${ }^{1}$ Senior scientific assistant, Psychological Educational Scientific Center, \\ Tashkent State Pedagogic University under the name of Nizami, Tashkent \\ ${ }^{2}$ Methodist ,Psychological Educational Scientific Center, $T$ \\ ashkent State Pedagogic University under the name of Nizami, Tashkent \\ ${ }^{3}$ Professor, DM. Department of ambulatory medicine and physical education, \\ Tashkent Pediatric Medical Institute, Tashkent \\ DOI: 10.31618/ESU.2413-9335.2019.5.61.30
}

ANNOTATION.

The objective. To study personal psychological peculiarities of pre-school age children with recurrent bronchitis. Materials and research methods. Thirty children with recurrent bronchitis (RB) in pre-school age from 5 to 7 years old ( basic group, average age 5,63 $\pm 0,31$ years old) underwent the study and prospective follow-up within the period from 2016 to 2017 at the pre-school educational facility №247. The control group involved 10 almost healthy children of the same age. Result. Conclusion. The achieved results testify high rate of family disorganization in the studied families, emphasizing the necessity of psychological correction with formation of adequate parents' attitude to the child's pathology with correct maternal choice of the educational strategy, which will increase the efficiency of rehabilitation of children with bronchial pulmonary pathologies.

\section{АННОТАЦИЯ.}

Цель исследования. Изучить психологические особенности личности детей дошкольного возраста с рецидивирующим бронхитом. Материал и методы исследования. В период с 2016 по 2017 гг. на базе дошкольного образовательного учреждения №247 Мирабадского района г. Ташкента исследованию и проспективному наблюдению были подвергнуты 30 детей дошкольного возраста от 5 до 7 лет (основная группа, средний возраст 5,63 $\pm 0,31$ лет) с рецидивирующим бронхитом (РБ). В контрольную группу вошли 10 практически здоровые дети аналогичного возраста. Результаты. Обсуждение. Полученные результаты свидетельствуют о высоком проценте семейной дезорганизации в исследуемых семьях, что подчеркивает необходимость психологической коррекции с формированием адекватного отношения родителей к болезни ребенка, с правильным выбором матерей тактики воспитания своего ребенка, которая повысит эффективность реабилитации детей при бронхолегочных заболеваниях.

Key words and concepts: personal psychological peculiarities, children, pre-school age, recurrent bronchitis

Ключевые слова и понятия: психологические особенности личности, дети, дошкольный возраст, рецидивирующий бронхит

Within the last decade a tendency for the intensification of the role of stress impacts, such as factors affecting health, was formed. Stress impacts can be risk factors for up to $90 \%$ of modern human pathologies. These are so-called "civilization sicknesses" appearing as a result of psycho emotional tension [1, p. 278-281, 6 , p. 65-67, 7, p. 275-276]. According to the data presented by L.P. Velikanova $(1998,1999)$ from 30 to $48 \%$ of the visits to doctor of parents with children are linked with psychological and social problems appearing due to emotional tension. Taking into account that most often children have respiratory pathology, that determines the necessity of extension of the search and study of the risk factors and criteria of psychological disorders in childhood. Many scientists admit that, a pathology, even caused by bare physical factors ones, can serve to be a source of emotional stress. Disorder of adaptation, which manifests in symptoms or syndromes of various nosologic forms of pathology, can be one of the outcomes of stress [2, p. 175-179, 4, p. 31-32]. Some authors made a conclusion that, for the definition of the progress and prognosis of somatic pathologies, together with clinical and paraclinical diagnostic methods it is also necessary to recommend psychological tests [3, 6, 152-155].

The objective. To study personal psychological peculiarities of pre-school age children with recurrent bronchitis.

Materials and research methods. Thirty children with recurrent bronchitis (RB) in pre-school age from 5 to 7 years old ( basic group, average age 5,63 $\pm 0,31$ years old) underwent the study and prospective followup within the period from 2016 to 2017 at the preschool educational facility №247. The control group involved 10 almost healthy children of the same age. Verification of the diagnosis of recurrent bronchitis was performed on the basis of 2009 "Working classification of the basic clinical forms of bronchial pulmonary pathologies in children". The study included assessment of family, genealogical, and social anamnesis; physical development and its harmony (anthropometric parameters: weight, height, BMI in compliance with WHO standards, 2011 [5, p. 134-138]; physical examination, measurement of AP, pulse, laboratory and instrumental tests. For the study of psychological characteristics of the children's personalities we used the following methods: conversation, observation, Varg-Stolen's poll about parental attitude, "kinetic family picture", and 
"Upbringing defects" quiz. Forty mothers of the studied children participated in the polls. Statistical processing of the data was performed on PC using Statistika 6.0. software. We calculated arithmetical mean (M), standard mistake $(\mathrm{m})$, relative values (prevalence in \%), Student's criterion $(\mathrm{t})$ with the calculation of error possibility $(\mathrm{P})$. differences of average values were considered to be reliable with $\mathrm{p}<0.05$.

Results of the research and discussion. In the process of the study we used a "parental attitude" poll method. Parental attitude means a system of various feelings towards a child, behavior patterns practiced in the communication with the child, specificity of perception and understanding of the child's character and personality and his deeds. The structure of the poll consists of 5 scales:

Scale 1 "Accepting - rejection" The scale reflects emotional integral attitude of a mother to a child. Results of the study showed that, the parameters of the scale of the mothers with children with $\mathrm{RB}$ with reliable difference $(15,5 \pm 0,3, p<0,001)$ were higher, than that of mothers of the children of the control group $(10,05 \pm 0,1)$. A parent feels anger, annoyance, irritation, and insult towards a child. There is neither trust nor respect to a child. It seems to the parent, that the child will not get any success in his life due to inabilities and low intellect.

Scale 2 "Cooperation" - socially required image of a parental attitude to a child. A parent is interested in a child's plans and business, he/she tries to help his child in everything, feels empathy to the child, thinks well about the child's intellectual and creative abilities, proud of the child. According to that scale mothers of the children of the basic group had values reliably lower $(5,6 \pm 0,2, p<0,01)$ compared to the scores of the moth-

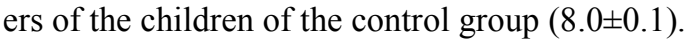

Scale 3 "Symbiosis". The scale reflects interpersonal distance in the communication with a child. Comparative analysis of average statistical parameters of the scale did not reveal reliable differences between the groups $(3,5 \pm 0,1,3,2 \pm 0,1$, respectively in the basic and control group). Symbiotic relationships between mothers and children, according to these parameters, are characterized by an average distance.

Scale 4 "Authority - hyper socialization". It reflects the form and direction of the control over a child's behavior. Mothers of sick children the parameters of the scale were high with a reliable difference $(4,9 \pm 0,2, p<0,001)$ compared to the control $(3,8 \pm 0,2)$. Parental authority of the mothers of sick children was manifested in the requirement of complete obedience and discipline and imposition of the parent's will to the child.

Scale 5 "Little looser". The scale reflects specificity of perception and understanding of a child by a parent. Distribution of the values, especially high rates for the mothers of the children with RB $(2,9 \pm 0,1, p<0,01)$ with a reliable difference compared to the control group $(1,15 \pm 0,1)$, shows a tendency for infatilization, attributing personal and social incompetence to a child. Parents see their child younger than he/she is in fact. Interests, thoughts, and feelings of the child are thought to be childish and not serious by the parents. A child is perceived as not adjusted and unsuccessful one (fig.1).

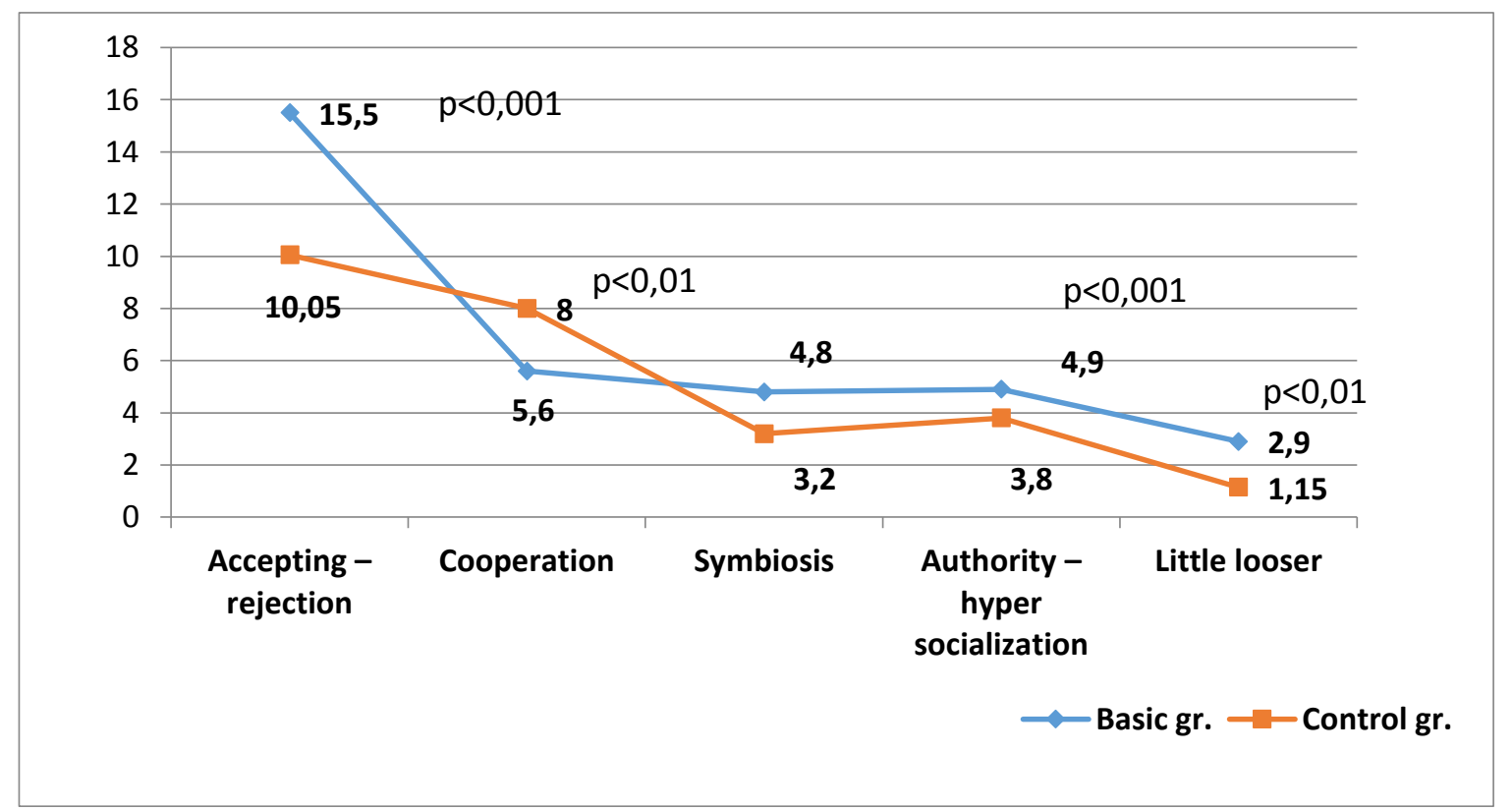

Figure 1. Distribution of the studied groups mothers' scores in the scales of "Parental attitude" poll

Thus, according to the results of the "Parental attitude" poll it is possible to reveal a dependence of the absence of a child's needs satisfaction on the disorder in the profound links between the child's and adult's worlds. That effects emotional status of a child, and determines early formation of negative personal feelings (anxiety, fears, neurotic complexes, communication barriers). All these surely effects the progress of the pathology and frequency of relapses.

The results of "Parental attitude" poll confirm the data of "Kinetic family picture" (KFP) projection method.

That test provides the notion of a child's subjective evaluation of his/her family, personality, his/her place in the family, his/her relationships with other 
members of the family. Family picture is a psychological picture of a child's personality. On the basis of the image performance and answers to the questions we can judge about specificity of perception of the relationships and emotional experience of a child in a family.

Pictures were analyzed according to several psycho-diagnostic parameters such as: 1 - location of human figure in the space (right, left, or central part of the paper - extra of inversion scale); 2 - number of rubbing out of the details and intensity of shading (anxiety scale); 3 - way of a tree depiction (cognitive style scale); 4 - depiction of family members and their absence, depiction of people not relevant to the family (power and weakness, ego scale); 5 - number of windows in the pictured house (open or close to contacts scale).

From the histories we revealed that, $46,7 \pm 0,3 \%$ $(\mathrm{p}<0,001)$ of the studied children were brought in incomplete families, versus $10,0 \pm 0,5 \%$ of the children of in the control group. Twelve children $(40,0 \pm 0,3 \%)$ of the basic group had expressive aggression. Child's "the self" was damaged by "the self" of child unwanted in the family with feeling of estrangement. According to the pictures of these children we could see that, they did not feel emotional contact warmness; in the families there was no heart warmness.

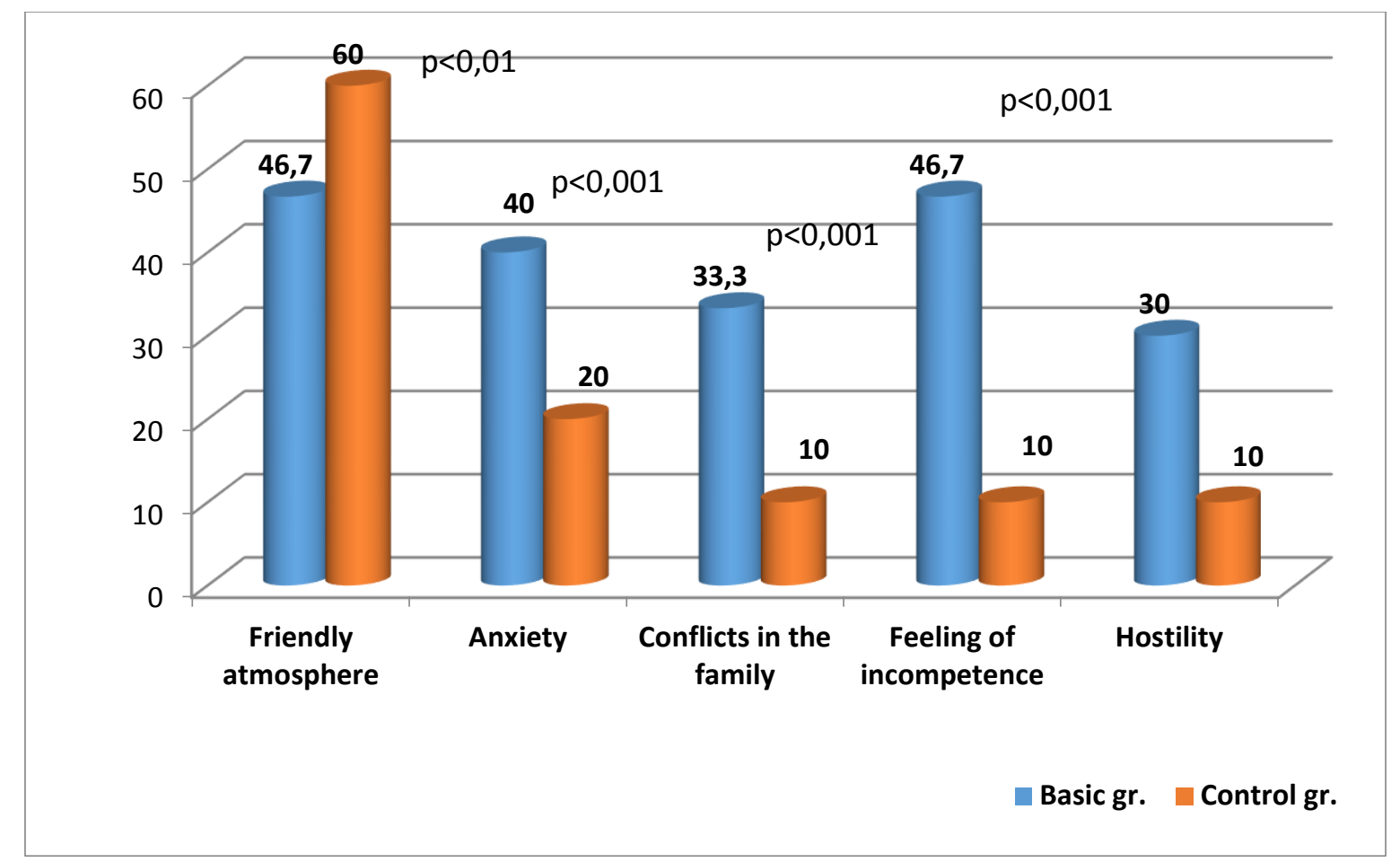

Figure 2. Prevalence of symptom complexes according to KFP assessment in the studied groups

According to KFP analysis results we determined five priority symptom complexes, with different characteristics of neuropsychological status: favorable family conditions, anxiety, family conflicts, feeling of incompetence, and hostility in family situations (fig.2).

As it s seen from the picture, children with RB reliably more often have anxiety, conflicts in the family, feeling of incompetence, and hostility compared to the control data.

A child draws not all family members. Usually a child doesn't draw those family members, who he/she has conflicts with. Most often these are cases, when it is difficult to adjust to a changed family situation after the birth of younger brothers and sisters, or negative attitude of children to the father who drank, was rude and angry towards family members.

Location of the family members in the picture often shows their relationships. So, for example, an important parameter of psychological closeness is a real distance between separate members of the family; children draw various objects serving the nature of the reasons separating them. In the group of the children with
RB we could see a picture where a father was sitting in a car or close to TV-set separating it from other members of the family. Mother is more often depicted with a baby in her hands taking her whole attention.

In the pictures of the children of the basic group we could see a common activity of several family members testifying presence of inner groupings in the family. For example, grandmother with grandfather, mother with father, and separately children. More often, exactly in $56,7 \%$ of the cases, children forgot to draw themselves. That indicated, probably, often absence of the child in the family, due to his/her staying in clinic. Children change family relationships and perception of these relations.

Drawing their family, some children $(46,7 \pm 0,3 \%)$ of the basic group, depicted all figures very small and located them in the lower part of paper. That indicated depression, and child's feeling of incompetence. In some pictures there was dominance of things, more often furniture, not people. We could guess about emotional anxiety of a child. It seems that a child postpones 
drawing of family members, drawing things possessing not so strong emotional importance.

It is considered that, a child spends more time drawing details and coloring figure of his ther favorite family member, and vice versa. In case of negative attitude to some family member a child depicts that person without details or without basic parts of body. When relationships of a child are conflicting and anxious we can note emotionally diverse colored figures: shading of the image, erasing and redrawing (in $40 \%$ cases).

Thus, KFP analysis results showed prevalence of aggressive, insincere or emotionally cold communication styles in the families of the children with RB. Among these children we revealed deeper and hardly correctable psychological alterations in the formation of business personal characteristics.

Similar tendency was registered in the analysis of the parameters of "Upbringing defects" poll. We determined three most important symptom complexes such as "hyper guardianship", "Cinderella type", and "unstable upbringing".

The type of family upbringing of the children of the basic group was dominantly maladjustment character with prevailing "hyper guardianship" upbringing type $(53,3 \pm 0,2 \%, p<0,001)$, while in the families bringing up healthy children there was no dominant disharmonic upbringing types.

Disorders of maternal upbringing such as "Cinderella type" - emotional neglecting (43,3 $\pm 0,4 \%$, $\mathrm{p}<0,001)$, and low degree of family organization, no value of moral aspects in the family, mother's active dominant conservatism and expressiveness have pathogenic character in the form of "unstable upbringing" $(36,7 \pm 0,5 \%, p<0,01)$, and promote development of the child's pathology relapse.

Conclusion. From the point of view of child's formation as a person, from five to seven years old there occurs intensive development $\mathrm{f}$ intellectual, moral and emotional spheres of personality. In that age children try to know themselves and others, choose a personal behavior line estimating his/her deeds. There is formation of business personal characteristics of a child. Inclination for practical and intellectual experiments, summarizing, and statement of cause-effect links is manifested.

During pre-school period of childhood, as well as during infancy and early childhood, one of the most important roles in the personal development of a child is still played by mother. Character of her communication with a child has direct effect on the formation of certain personal characteristics and types of behavior. Desire to be approved by mother becomes one of the behavioral stimuli for a child.
Undoubtedly, the bases of psychological health of a child are set in a family. Unique primary society gives children the feeling of protection, "emotional background", support, unevaluated perception. Adults try to give their children the best, while modern medicine insists that from 30 to $40 \%$ of chronic diseases have psychogenic origin.

Results of modern studies directly testify presence of interrelation of the disorders of psychological health with somatic ones. Expressed anxiety, inner tension, and fears are some of these disorders of psychic health, able to cause further decrease of adaptive capabilities of body and development of a pathology.

In that perspective, the results achieved by us testify a high per cent of family disorganization in the studied families, emphasizing the necessity of psychological study of not only a child, but his/her family also. Psychological consultation should be targeted to formation of adequate attitude of parents to a child's pathology and widening of parents' understanding of family factors conditioning development of somatic pathology. The work on the development of maternal personality and assistance in the choice of correct strategy of child's upbringing will increase the efficiency of medical rehabilitation in the cases of bronchial pulmonary diseases in children.

\section{References}

1. Antropov U.F., Shevchenko U.S. Treatment of children with psychosomatic disorders. SPb. Speech. 2002 p 560. (in Russian)

2. Vein A.M. Vegetative disorders. Symptoms, diagnostics, therapy. M. Medicine. 2000. P.752 (in Russian)

3. Kovineva O.G., Vvedenski V.N. Psychological characteristics of pre-school age children // Universum: Psychology and education: E-Jour. 2017. № 11(41).URL: http://7universum.com/ru/ psy/archive/ item/ 5249 (in Russian)

4. Mizernitski U.L., Tsaregorodtsev A.D. What is hidden under the diagnosis of recurrent bronchitis in children Russian bulletin of perinatology and pediatry. 2003. №6. p. 31-33 (in Russian)

5. Medical bases of physical education and sport in the formation of harmonically developed generation. Guideline. Editors: A.I. Ikramov, D.I. Akhmedova, et al. Tashkent. 2011. p148 (in Russian)

6. Psychosomatics: the newest reference book. M. EXMO. 2003. P.443 (in Russian)

7. Ortega A.N., Huertas S. E., Canino G.,et al. Childhood asthma, chronic illness, and psychiatric disorders. J.Nerv.Ment. Dis. 2002. 190 (5). 275-281. 